\title{
MONTE CARLO MODELING OF THE FORMATION OF VERY SMALL DROPS
}

\author{
A. M. Ovrutsky, A. O. Rozhko, Z. U. Tchelbaevsky \\ Physics Faculty, Dnipropetrovs'k National University, \\ Dnipropetrovs'k, UA-49050, Ukraine \\ e-mail: metal@ff.dsu.dp.ua
}

(Received January 25, 2005; received in final form March 2, 2006)

\begin{abstract}
Monte Carlo simulation of the drop formation has been carried out for one-component and binary systems. A model of lattice liquid with vacancies was used. Activation energies for the interexchange between the atoms and the vacancies were calculated after counting all the nearest neighbors of both. The shapes of drops and wetting angles were studied for different interactions of atoms of the main component and an added component with the substrate. An active added component improves wetting but a very active component impedes spreading of liquid along the substrate. Some solutions were obtained for the cases when crystallization of one component or dissolution of the substrate took place. A crystal phase appearing on the substrate detains liquid spreading. A partially dissolved substrate does not restore its shape after crystallization.
\end{abstract}

Key words: modeling, liquid, vacancies, drop shapes, wetting, crystallization.

PACS number(s): 81.10.Aj; 68.35.Rh; 81.05.Ys; 81.15.Hi; 02.70.Lq; 74.70.Ad; 81.10.Fq

\section{INTRODUCTION}

The formation of droplets including their spreading along a substrate relates to many fundamental and applied problems [1]. Different computer simulation methods are used to describe these processes: the real-coded lattice gas method as a kind of a particle-based fluid model $[2,3]$, a three-dimensional simulation for the lattice Boltzmann model [4,5], atomistic simulations via molecular dynamics method [6,7]. Each method is suitable for a certain length scale. For instance, mesoscopic droplets with micron length scale were considered in in $[3,5]$. Atomistic molecular dynamics simulations are used for systems containing tens of thousands of atoms. Larger systems (with the length scale of 0.01 microns) may be studied by means of atomistic Monte Carlo simulations.

Nowadays kinetic modeling through Monte Carlo simulations is widely applied for different processes occurring at the phase boundaries [8-10]. The traditional method for the simulation of the crystal growth using a model of lattice gas in an approximation "solid on solid" was developed in [11-13]. Three-dimensional simulations were used in the papers [14-16]. But there is no good agreement between the results obtained within the lattice gas model with experimental data concerning roughening of the interface. The Monte Carlo simulation in this case [17-19] gives very high values (in comparison with experimental data) of dimensionless entropy of fusion $\left(\Delta S=\Delta H_{m} / k T \cong 4.8\right.$ for a simple cubic structure, $\Delta H_{m}$ is the melting heat, $k$ is the Boltzmann constant, $T$ is temperature) which corresponds to the roughening transition (transition from faceted to rounded forms of growth). The interface becomes too wide at small values of entropy, and two phases do not exist separately if parameters of metals are used for simulations. The main shortcoming of the lattice gas model is the way it attaches atoms to a crystal without the energy barrier [20].

The problem of modeling the drop formation, includ- ing an interaction of atoms with a substrate is the problem of modeling a liquid first of all. The full understanding of diffusion processes and flow mechanism in liquid has not been achieved by now. Activation energies for such processes are small enough (in comparison with such values for the diffusion in solid): these are approximately two times the heat of melting [21] or 12-17 per cent of the heat of evaporation [22]. Therefore motions of atoms occur frequently.

If several possible events may happen to an atom, the probabilities corresponding to them should be defined through the Boltzmann factor at Monte Carlo kinetic modeling. The time scaling, i.e. determination of time step, associates usually with the smallest activation energy [12,13]. The time step will be small for liquid $\left(\leq 10^{-11} \mathrm{~s}\right)$. The Monte Carlo method of modeling is more suitable for the solid state for which energy barriers are much larger. But it is advantageous because of the fact that all energy parameters which are necessary for calculating probabilities can be determined from tabular and diagram data. In this paper we apply the model of lattice liquid for studying the drop formation including processes of wetting and crystallization.Our model differs from the model of lattice gas in the following points: the liquid contains vacancies that provide diffusion, atoms of liquid have to overpass the energy barrier that depends on their nearest surrounding in order to be attached to a crystal.

\section{MODEL AND SIMULATION METHOD}

It is known that the shapes of small crystals growing from the melt are rounded or partly faceted; it depends on the degree of kinetic roughening [18,19], i. e. the frequency of jumps of atoms at the interface boundary. The crystal-vapor interface is usually sharp. However, we hoped that the drops of lattice liquid with a sufficient number of vacancies will have large surface roughness 
and rounded forms. The mobility of atoms occurs by the mechanism of their exchange with the vacancies in the model of lattice liquid. We assume also that the process of attaching an atom to a crystal is an activation process and the energy barrier is a function of the number of its nearest neighbor atoms in the liquid. Atoms relating to the crystal phase will be referred to as "solid" atoms and atoms of liquid - "liquid" atoms. "Solid" atoms are surrounded only by "liquid" atoms, otherwise "liquid" atoms which have only "solid" atoms as nearest neighbors cannot exist in this state. A "liquid" atom which has "solid" atoms as nearest neighbors may be attached to the crystal cluster; after that it becomes "solid". Single atoms are "gas" atoms.

The initial form of drops was a cube, the same as in [3]. Atoms were placed together with a small number of vacancies on the sites of the vcc or fcc crystal lattice in a part of cube vessel with ideal walls. The sites of the free volume of the vessel were vacant. The planes (001) of the crystal lattice were chosen parallel to the substrate. We assumed that atoms placed near the substrate have 4 bonds with its atoms. We used usual three-dimensional arrays, every three indices responded to a certain lattice site. The integer value of an element of array (site $[x, y, z])$ indicates the presence of an atom at the given position and gives its characteristics (if $\operatorname{site}[x, y, z]=0$ this position is vacant; if site $[x, y, z]=1$, a "liquid" atom of $A$ component is placed in this position; if $\operatorname{site}[x, y, z]=2$, a "liquid" atom of $B$-component; and if it is 3 , an atom of the substrate; and, finally, if it is 5, a "solid" atom of $B$-component is there).

Vacancies disturb the local order in atom arrangement, and their motion near the interface (between the volume filled by atoms and exterior volume) causes kinetic roughening. The interface formed in a course of the simulations becomes rounded. Besides that, the vacancy diffusion leads to the equilibrium concentration of vacancies in a condensed part of the system.

The average energy barrier is taken into consideration in analytical theories of diffusion. But in reality atoms may have a different surrounding. In our model the energy barrier for atom jumping into the vacant site depends on the numbers of the nearest neighbor atoms in old and new positions. It is comparatively small in the case when this number does not change. But in the case of this quantity decreasing the energy increases by the magnitude of energy of the broken bonds (energy of evaporation per one bond is $f_{1}=2 H_{\mathrm{ev}} / z, H_{\mathrm{ev}}$ is enthalpy of evaporation, $z$ is the coordination number). Probabilities of such motions (with large energy barrier) are small. Probabilities of detachment of atoms from a drop surface are very small (several bonds must be broken). "Gas" atoms appear if such events happen, they have $z$ neighbor vacant sites and jump into the randomly chosen vacant site during each time step. If a "gas" atom appears near other atoms, it will be joined to them in this time step.

Several different events can happen to an atom in our model, for example, a "liquid" atom can fill-in this or another vacant site if they are placed near it or to be at- tached to a crystal phase. The energy of interaction with the neighbor atoms (and with a substrate for some atoms under consideration) may be distinguished for different new possible positions. We could not apply the economical scheme of simulations $[23,24]$ (in this scheme in every cycle an atom attaches to or detaches from the crystal) which is applicable to events of one type only.

A time step $\tau$ was defined from the condition that the most probable event will take place necessarily for this time (probability equals 1 ) and probabilities of other possible events were calculated in relation to it. All atoms were tested randomly with respect to all of the events which can happen to them over time $\tau$ (till the first success). This process was repeated and the real time was known exactly.

The most probable event in our model for the case of a pure liquid state is the surface migration of an atom under the condition of the constant number of the nearest neighbor atoms. We have chosen the energy barrier $f_{c}$ for such a displacement less than $0.1 H_{\mathrm{ev}}$ ) (as mentioned above, the middle activation barrier for diffusion in liquid is roughly $0.15 H_{\mathrm{ev}}$ ). Therefore $\tau$ may be found from the relation

$$
P(\tau)=\tau \nu_{0} \exp \left(-f_{c} / k T\right)=1
$$

where $\nu_{0}$ is the frequency of atom oscillations. The sum of probabilities to fill-in or not to fill-in will equal 1 for any randomly chosen direction of atom motion and for any surrounding.

Another equation in which the sum of two largest probabilities equals 1 was used to determine $\tau$ if crystallization was taken into consideration and events of different kind (solid-liquid "transformation" of atoms or jumps into vacancies) could happen (the third event, if nothing has taken place, the sum of probabilities for three events equals 1 in any case).

The probability of atom filling-in a vacancy was calculated according to the relation

$$
P_{v}=\tau \nu_{0} \exp \left[\left(-f_{v}\left(z_{1}\right)-\Delta u\left(\Delta z_{1}\right)\right) / k T\right]
$$

where $f_{v}\left(z_{1}\right)$ is the energy barrier in the case when the number $z_{1}$ of the nearest neighbors does not change, $f_{v}\left(z_{1}\right)=f_{c}+0.2 f_{c}\left(z_{1}-4\right)$ for $z_{1}>4$ (if $z_{1} \leq 4$, the atom is the surface atom and activation energy for diffusion is minimal in this case); $\left.\Delta u\left(\Delta z_{1}\right)=\mid \Delta z_{1}\right) \mid f_{1}$ is the energy of broken bonds in the case when $z_{1}$ decreases $\left(f_{c}=(0.15 \div 0.2) f_{1}\right)$. Interaction of atoms with the substrate is taken into account when calculating $\Delta u\left(z_{1}\right)$ for the first layer, the additional factor is $\exp \left(-b_{s} n_{s} f_{1} / k T\right)$ $\left(n_{s}\right.$ is the number of bonds with the substrate $n_{s}=4$; $b_{s}=0$ if there is no attraction or repulsion - the energy of one bond with the substrate is equal to the energy of the liquid-liquid bond $V_{l l}=f_{1}$. Full energy of interaction with the substrate is $\left.4\left(1+b_{s}\right) f_{1}\right)$; the change of energy after a jump of an atom of A-component away from the substrate is $4 b_{A s} f_{1}$. Thus, after choosing a random direction for possible atom jumping it is necessary 


\section{A. M. OVRUTSKY, A. O. ROZHKO, Z. U. TCHELBAEVSKY}

to count up the number of the nearest neighbors for its new position.

Two procedures, simulating action of a surface tension were used to stabilize the surface of liquid with gas (to reduce its roughness). The first was for the correction of sites with a negative curvature. We assumed that vacancies may move with small energy activation (the factor $\exp \left(-f_{v}\left(z_{1}\right) / k T\right)$ only) if $z_{1}$ is more than $m(m=9$ for fcc structure and $m=6$ for the vcc lattice) and $\left|\Delta z_{1}\right|$ is less than 3 ( 2 in the case of the vcc lattice). Therefore, the vacancies may move from narrow cavities of the surface into the liquid (equilibrium concentration of vacancies becomes larger if this is the case). The second procedure corrects protuberances of the surface. The surface atom, which has more than 5 neighbor vacancies, may be moved closer up to a crystal. Therefore, it has been attached to the atom which had only one or two neighbor vacancies if probability for energy barrier $u_{P} \approx H_{\mathrm{ev}} / 5$ (this value has been chosen after the comparison of several various solutions) allowed such a move. Two atoms have been placed into one lattice site as a result (comparatively large black squares in Fig. 1) but they would be separated at the next trial.

We assumed that crystal clusters might appear only on the substrate. The probability of the formation of a crystal cluster from three atoms was calculated as the Boltzmann factor from the work of forming all solidliquid bonds (surface energy per one such bond is roughly $\varphi=\Delta H_{m} / z$, where $\Delta H_{m}$ is the melting heat of a component which may crystallize) or as multiplication of probabilities for two atoms to be attached to some chosen atom. Both methods give close results because kinetics of attachment and detachment of atoms defines the distribution of clusters in sizes mainly and only a very small amount of them may reach the size of a critical nucleus.

The probability for a chosen atom to be attached to a crystal cluster was calculated according to

$$
P^{+}=\tau \nu_{0} \exp \left[\left(\Delta \mu-2 n_{1} \alpha \varphi-\Delta H_{m}\right) / k T\right]
$$

where $n_{l}$ is the number of 1-1 "liquid-liquid" bonds of the atom which may be attached; $2 \alpha \varphi(\alpha<1)$ is the energy barrier in the case only one "liquid" neighbor; $\Delta \mu=\Delta H_{m}\left(T_{0}-T\right) / T_{0}$ is the difference of chemical potentials for the component which may crystallize; $T_{0}$ is the equilibrium temperature (the melting point or liquidus temperature in the case of binary melts). The energy barrier $2 n_{1} \alpha \varphi$ is necessary; otherwise two phases (liquid and solid) do not exist separately for parameters of metal (see above). The factor $\exp \left(-\Delta H_{m} / k T\right)$ is necessary for dynamic equilibrium at the temperature $T_{0}$.

The probability for an atom to be detached from a crystal is

$$
P^{-}=\tau \nu_{0} \exp \left[-2 n_{s}(1+\alpha) \varphi / k T\right]
$$

where $n_{s}$ is the number of s-s bonds ("solid"-"solid") of the atom which may be detached. The energy barrier is $2(1+\alpha) \varphi$ per one s-s bond, it is the sum of difference in energies of interaction $\left|V_{s s}-V_{s l}\right| \cong 2 \varphi$ and the additional barrier $2 \alpha \varphi$. Probabilities $P^{+}$and $P^{-}$must equal each other at the temperature $T_{0}(\Delta \mu=0)$ if $n_{s}=n_{l}=z / 2$, i.e. for atoms in positions at kink of a step. The factor $\exp \left(-\Delta H_{m} / k T\right)$ that appears in (3) was determined from this condition.

In order to visualize the results of simulations, the images of different sections of the simulation box (usually $50 \times 50 \times 30$ in units of lattice constant) were produced. Such a lattice contains 150000 atom sites (in the case of the vcc structure) and from 20000 to 40000 of atoms was placed in the initial volume of drops. Calculations were fulfilled until the shapes of drops become stable. Roughly 10000-15000 steps of time, i.e. $10^{9}-10^{10}$ Monte Carlo cycles (trials) were needed for that.

Fig. 1 shows an example of drop section (onecomponent liquid). The light grey band from above indicates the substrate. There are dark grey squares under it; they indicate "solid" atoms. Crystal clusters at equilibrium conditions fill the first layer because it was assumed that the substrate could not be dissolved. But the next layer (second from above) is filled only partly; a dynamic equilibrium of crystal and liquid phases takes place.

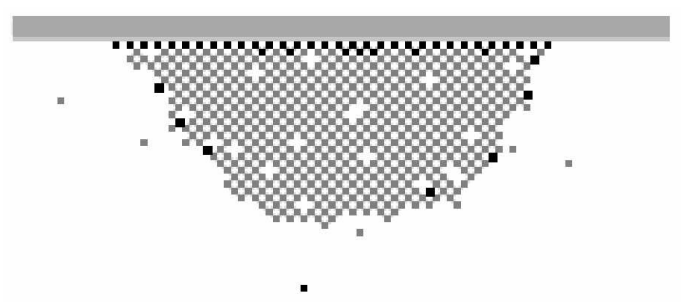

Fig. 1. The example of a drop section fcc structure $(\mathrm{Cu}$, $\left.T_{m}=1356 \mathrm{~K}\right), t b_{s}=0, t f_{c}=0.5 \Delta H_{m}, u_{P}=f_{1}$.

Contact angles were measured at the middle sections (perpendicular to the substrate) of drops; their dependencies on energy of the interaction with the substrate were determined.

Simulations have been carried out for parameters that respond to liquid $\mathrm{Cu}$ (fcc structure) or Fe (vcc structure) near the melting point $\left(T_{m}\right)$ and for binary melts: hypothetical alloys $A-B$ with 20 atom $\%$ of $B$-component ( $A$-component is $\mathrm{Fe}$ or $\mathrm{Cu}$ ) and the $\mathrm{Cu}-\mathrm{Ni}$ alloy (30 atom $\% \mathrm{Ni}$ ) near the equilibrium temperature of liquidus. The choice of systems is such because copper and iron are often used as basic components of alloys for joining or welding. The energies of interactions of different atoms in a liquid solution were taken as in an ideal solution, $V_{l l_{A B}}=0.5\left(V_{l l_{A A}}+V_{l l_{B B}}\right)$ for the $\mathrm{Cu}-\mathrm{Ni}$ alloy and $V_{l l_{A B}}=V_{l l_{A A}}=f_{1}$ for the hypothetical alloys; it was assumed for the interaction of "liquid" atoms with crystal nuclei that $V_{l s A B}=V_{l l_{A B}}$. 


\section{RESULTS}

Forming of droplets of pure liquids ( $\mathrm{Fe}$ and $\mathrm{Cu}$ ) was studied for the cases of different interaction of atoms with the substrate (different values of factor $b_{s}$ ). Fig. 2 shows drop sections. The real time which is necessary to reach an equilibrium form of drops (fluctuations of drops ${ }^{6}$ shapes take place all the time) is roughly $10^{-8}-10^{-7} \mathrm{~S}$ (the outcome of multiplying the number of trials of every atom and the time step $\tau$ ) for majority of cases here and below. The distinctions in the forms shown in Fig. 2 are connected with the magnitude of the parameter $b_{s}$. Atoms may move along the surface of a substrate and come off from it (to evaporate), if this parameter is small.

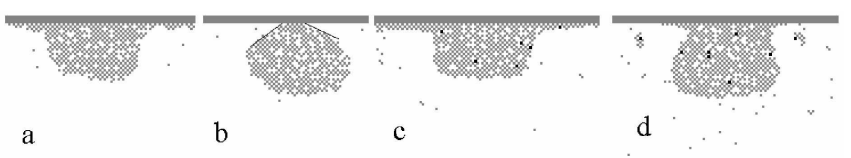

Fig. 2. Droplets of pure melts. (a), (b) $-\Delta H_{m} / k T_{0}=0.98$ $(\mathrm{Cu}), T=T_{0}=1356 \mathrm{~K}, H_{\mathrm{ev}} / k=36650 \mathrm{~K}, u_{p}=f_{1}$, $f_{c}=0.17 f_{1}, b_{s}=0.2$ for (a) and -0.08 for (b); (c), (d) $\Delta H_{m} / k T_{0}=1.03(\mathrm{Fe}), T=T_{0}=1808 \mathrm{~K}, H_{\mathrm{ev}} / k=40000 \mathrm{~K}$, $u_{p}=f_{1}, f_{c}=0.2 f_{1}$

The evaporation of atoms detains the spreading of drops in the case of the vcc structure $(\mathrm{Fe})$, the spreading is practically absent if $b_{s}<0.05$ (Fig. 2,d). Atoms evaporate from the substrate (at small $b_{s}$ ) because they do not have the nearest neighbors in the atom layer and cannot jump directly into the neighbor places on the substrate in the case of the vcc structure. But single atoms become motionless on the substrate at the significant values of $b_{s}\left(b_{s}>0.2\right)$.

In the case of the fcc structure $(\mathrm{Cu})$, atoms have four bonds with the substrate and may have four nearest neighbor atoms in the layer. There is a much smaller quantity of "gas" atoms in the case of the fcc structure of liquid (Fig. 2,a and b). Thus, drops spread much better. The wetting is absent at the negative values of parameter $b_{s}$ (Fig. 2,b).

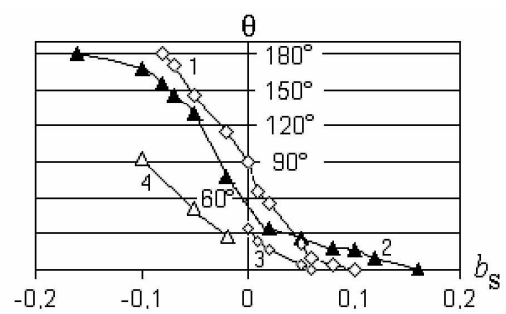

Fig. 3. Wetting angles $(\Theta)$ plotted against values of the parameter $b_{s}, 1,3$ - vcc structure $(\mathrm{Fe}) ; 2,4-$ fcc structure $(\mathrm{Cu}) ; 3,4-$ with adding a surface active $B$-component $(20 \%) ; 3-b_{B s}=0.1 ; 4-b_{B s}=0.2$.
Wetting angles plotted against the values of parameter $b_{s}$ are shown in Fig. 3 . These are evaluated automatically when we drew a line on the image of the droplet section by a cursor (see Fig. 2,b). The angles were measured for stationary forms, but fluctuations of drop shapes impede measurements. Each point on graphics is average from ten measurements at least; error bars on the contact angles is $4 \div 7^{\circ}$. As it follows from the data obtained, complete wetting occurs as a result of a slight enhancement of the liquid-substrate interaction (slight increasing of the parameter $b_{s}: b_{s} \cong 0.08$ for the vcc structure and $b_{s} \cong 0.16$ in the case of the fcc structure). The same interaction as in liquid gives angles near $90^{\circ}$. Certain negative magnitudes of $b_{s}$ are necessary to reach full non-wetting (see curves 1 and 2).

Fig. 4 shows drops of binary liquids ( $A$-component is $\mathrm{Cu}$ or $\mathrm{Fe}$ ) at different interactions of components with the substrate. The surface-active $B$-component may improve wetting (see curves 3 and 4 in Fig. 3). Wetting takes place also in the case of weak "repulsion" $\left(b_{s}<0\right)$ of the main $A$-component from the substrate (Fig. 4,a). But very active $B$-component may stop the spreading of small drops (Fig. 4,b) because jumps of $B$-atoms along substrates become improbable and they hinder jumps of $A$-atoms. Drops are spreading more quickly (the time of approaching the stable shapes of drops is much less) if the second component is moderately active (Fig. 4,c).

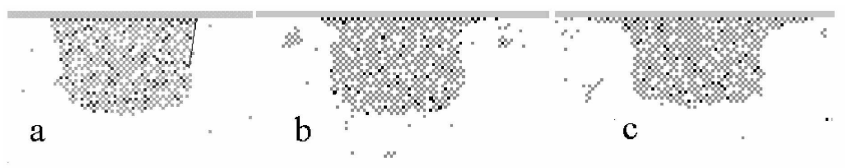

Fig. 4. Sections of drops of binary melts (20\% of $B$-component), (a) - fcc structure, $T_{0}=1150 \mathrm{~K}$; (b) and (c) - vcc structure, $T_{0}=1550 \mathrm{~K}$; for (a), (b) and (c) $b_{A s}=-0.08,0.05,0.05$; for (a) and (b) $b_{B s}=0.2$; for (c) $b_{B s}=0.1$.

The sections of drops in which the second $B$ component $(\mathrm{Ni})$ is crystallizing or dissolving are shown in Fig. 5 (hypothetical $\mathrm{Cu}-\mathrm{Ni}$ alloy without solubility in solid). Crystallization hinders the spread of a drop at the beginning (Fig. 5,a). But the drop can spread later, when B-atoms are in compact crystals mainly (Fig. 5,b).

Fig. 5,d-f shows dissolution and growth of the substrate that is the crystal of $B$-component (initial section is shown in Fig. 5,c). At the beginning the binary melt was superheated to $100 \mathrm{~K}$ higher than the equilibrium temperature (the liquidus temperature) $\left(T_{0}=1500 \mathrm{~K}\right.$, $T=1400 \mathrm{~K}$ ); then, after a partial dissolution of the substrate, the melt was supercooled to $100 \mathrm{~K}$ below the equilibrium temperature $(T=1400 \mathrm{~K})$. The drop spreads much better when dissolution takes place because new "liquid" atoms of $B$-component, which appear as a result of the dissolution, keep the atoms of $A$-component from evaporation. 


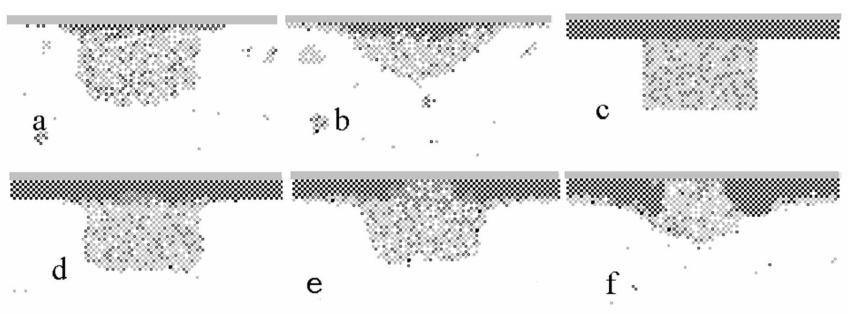

Fig. 5. Crystallization of $B$-component (a), (b), (f) and dissolution of the substrate (d) and (e), $\mathrm{Cu}-\mathrm{Ni}$ alloy (30 atom $\% \mathrm{Ni}, T_{0}=1500 \mathrm{~K}, \Delta T=T_{0}-T=100 \mathrm{~K}$ or $\left.-100 \mathrm{~K}\right)$, substrate is Ni. $\left(\Delta H_{m} / k T_{m}=1.24, H_{\mathrm{ev}} / k=45800 \mathrm{~K}\right)$. $A$-component from evaporation.

It is interesting that liquid of $A$-component is kept above the surface of the substrate when $B$-component crystallization is practically finished, and the substrate is not restored in it previous form in the region of spreading of the drop (Fig. 5,f).

\section{CONCLUSION}

A model of lattice liquid is developed for simulating formation of very small drops. Despite some shortcomings of our model (rather high concentration of vacancies is necessary to decrease the influence of crystal lattice and the atoms of "gas" move randomly even if they do not collide with each other) the results obtained are quite interesting. The simulations provide some visualization of the processes that take place on a atomic scale. It is demonstrated how the energy parameters influence the wetting of the substrate and spreading of a liquid. Complete wetting occurs as a result of a slight enhancement of the liquid-substrate interaction (parameter bs characterizing the additional interaction is small enough for the complete wetting: $b_{s}=0.08$ for the vcc structure or 0.16 for the fcc structure). An added active component improves wetting but in the case of a very active component, for which the interaction with the substrate is strong enough, the liquid does not spread along the substrate.

The concentration of atoms in "gas" phase near the substrate is high when the interaction with it is weak. Some evaporation of a liquid film at the substrate may influence the process of wetting.

Crystallization of the second component may delay the spreading of drops. The dissolution of the substrate positively influences the spreading of drops. There are changes of surface of the substrate if it was partially dissolved under superheated droplets of binary liquids and then the crystallization of one component took place.
[1] P. G. de Gennes, Rev. Mod. Phys. 57, 827 (1985).

[2] M. Malevalents, R. Kapral, Europhys. Lett. 44, 552 (1998).

[3] Y. Hashimoto, S. Tanaka, H. Ohashi, Trans. JWRI 30, 101 (2001).

[4] M. R. Swift, E. Orlandidi, W. R. Osborn, J. M. Yeomans, Phys. Rev. E 54, 5051 (1996).

[5] A. Dupuis, A. J. Briant, C. M. Pooley, J. M. Yeomans, prepint cond-mat/0303082 (2003).

[6] E. B. Webb III, G. S. Grest, D. R. Heine, Phys. Rev. Lett. 91, 236102 (2003).

[7] E. B. Webb III, J. J. Hoyt, G. S. Grest, D. R. Heine, J. Mater. Sci. 40, 2281 (2005).

[8] H. Chuan Kang, W. H. Weinberg, Surf. Sci. 299-300, 755 (1994).

[9] Ch. Heyn, C. Dumat, J. Cryst. Growth 227-228, 990 (2001).

[10] M. Vladimirova, A. Pimpinelly, A. Videcod, J. Cryst. Growth 220, 631 (2000).

[11] A. A. Chernov, J. Levis, J. Phys. Chem. Sol. 28, 2181 (1967).

[12] G. H. Gilmer, P. Bennema, J. Appl. Phys. 43, 1347 (1972).

[13] G. H. Gilmer, J. Cryst. Growth 36, 15 (1976).

[14] A. V. Zverev, I. G. Neizwestny, N. L. Schwarz, Z. Sh. Yas- nowidskaya, Fiz. Tekhn. Polupr. 35, 1067 (2001).

[15] W.-M. Wang, J.-M. Liu, X. Y. Chen, Z. G. Liu, J. Cryst. Growth, 240, 313 (2002).

[16] Y. Akieama, N. Imaishi, Y.-S. Shin, S.-C. Junk, J. Cryst. Growth 241, 352 (2002).

[17] R. F. Xiao, J. Alexander, D. Iwan, F. Rosenberger, Phys. Rev. A 43, 2977 (1991).

[18] P. J. C. M. van Hoof, W. J. P. van Enckevort, M. Schoutsen, J. Cryst. Growth 193679 (1998).

[19] A. M. Ovrutsky, I. G. Rasin, Trans. JWRI 30, 239 (2001); Poverkhnost'. Rentg., sinkhrofazotr. i neytr. issledovaniya 12, 65 (Moscow, 2002).

[20] A. M. Ovrutsky, M. S. Rasshchupkina, A. A. Rozhko, Poverkhnost'. Rentg., sinkhrofazotr. i neytr. issledovaniya 1, 85 (Moscow, 2006).

[21] B. S. Bokshteyn, L. M. Klinger, E. N. Uvarova, Amorfnye metallicheskie splavy [Diffusion in amorphous alloys] (Metallurgy, Moscow, 1983), p. 81 (in Russian).

[22] K. J. Smithells, Metals Reference book (Butterworths Publishers, London \& Boston, 1976), p. 446.

[23] A. B. Bortz, M. H. Kalos, J. L. Lebovich, J. Comp. Phys. 17, $10(1975)$.

[24] H. M. Cuppen, E. van Veenendaal, J. van Suchtelen, W. J. P. van Enckevort, E. Vlieg, J. Cryst. Growth 219, 165 (2000). 


\section{МОДЕЛЮВАННЯ ФОРМОУТВОРЕННЯ ДУЖЕ МАЛИХ КРАПЕЛЬ ЗА МЕТОДОМ МОНТЕ-КАРЛО}

А. М. Овруцький, А. О. Рожко, З. Ю. Челбаєвський

Фізичний факультет, Дніпропетровсъкий націоналъний університет,

Дніпропетровсък, 49050, Украӥна

Моделювання формоутворення крапель за методом Монте-Карло виконане для однокомпонентних та бінарних систем. Використано модель граткової рідини. Розрахунок енергій активації для обміну атомів місцями з вакансіями проведено після визначення найближчого оточення обраного атома й вакансії. Форми крапель та кути змочування були вивчені для різної взаємодії атомів основного компонента та атомів доданого компонента з підкладкою. Активний доданий компонент поліпшує змочування, але дуже активний компонент заважає розтіканню рідини по підкладці. Декілька розв'язків отримано для випадків, коли відбувалася кристалізація одного з компонентів або розчинення підкладки. Кристалічна фаза, що з'являється на підкладці, затримує розтікання рідини. Підкладка, яка була частково розчинена, не відновлює своєї форми після кристалізації. 